\title{
Somatic Embryogenesis and Plant Regeneration in Wedelia calendulacea Less. an Endangered Medicinal Plant
}

\author{
Shamima Akhtar Sharmin ${ }^{1,2,5}$, Md. Jahangir Alam ${ }^{3}$, Md. Mominul Islam Sheikh ${ }^{4}$, Kanak \\ Kanti Sarker ${ }^{2}$, Muhammad Khalekuzzaman ${ }^{5}$, Md. Anwarul Haque ${ }^{6}$, Mohammad Firoz \\ Alam $^{2}$ and Iftekhar Alam ${ }^{1,2 *}$ \\ ${ }^{I}$ Division of Applied Life Sciences; Gyeongsang National University; Jinju - Republic of Korea. ${ }^{2}$ Department of \\ Botany; University of Rajshahi; Rajshahi - Bangladesh. ${ }^{3}$ Department of Bioscience (Integrated Bioscience Section); \\ Graduate School of Science and Technology; Shizuoka University; Shizuoka - Japan. ${ }^{4}$ Department of Environmental \\ Materials Science; Gyeongsang National University; Jinju - Republic of Korea. ${ }^{5}$ Department of Genetic \\ Engineering \& Biotechnology;University of Rajshahi; Rajshahi - Bangladesh. ${ }^{6}$ Department of Biotechnology and \\ Genetic Engineering; Islamic University; Kushtia - Bangladesh
}

\begin{abstract}
In this work, plant regeneration via somatic embryogenesis was achieved from leaf and internode derived callus of Wedelia calendulacea, an endangered medicinal plant. Primary callus was induced by culturing leaf disc and internode explant on Murashige and Skoog medium supplemented with $2.0 \mathrm{mg} \mathrm{L}^{-1}$ of 2,4-D under light condition. Transfer of embryogenic callus on a reduced concentration of 2,4-D facilitated somatic embryo development while calluses remained unorganized at the same 2,4-D level. A histological analysis confirmed somatic embryo by revealing the presence of a closed vascular system in the developing embryos and lack of a vascular connection with surrounding callus tissues. Somatic embryos germinated into plantlets upon transfer on MS medium containing 1.0 $m g L^{-1}$ BAP plus $0.5 \mathrm{mg} \mathrm{L}^{-1} G A_{3}$. Plantlets were acclimatized successfully and survived under soil condition. This is the first on somatic embryogenesis of $\mathrm{W}$. calendulacea. This result could facilitate genetic transformation of this important medicinal plant.
\end{abstract}

Key words: In vitro, Medicinal plant, Micropropagation, Somatic embryo, Threatened, Wedelia calendulacea Abbreviations: BAP: 6-benzylaminopurine, $\mathrm{GA}_{3}$ : gibberellic acid, NAA: napthalene acetic acid, PGR: plant growth regulator

\section{INTRODUCTION}

Wedelia calendulacea Less. belonging to the Asteraceae family, is a perennial herb, with light camphor-like odor. The plant is traditionally used as a tonic for hepatic and splenic enlargement, and in skin diseases. Historic use of $W$. calendulacea as liver tonic is scientifically confirmed. The alcoholic extract of the whole plant exhibit protective activity against liver injury and stimulates liver secretory capacity (Varsha et al. 2011). Coumestans isolated from the leaves has protective action against paracetamol induced liver damage by increasing serum enzyme levels (lactate dehydrogenase, alanine and aspartate transaminase and alkaline phophatase) (Emmanuel et al. 2001). The herb containing isoflavanoids and wedelolactone is used in various liver disorders, uterine hemorrhage menorrhagia and post-menopausal osteoporosis (Annie et al. 2006).

\footnotetext{
*Author for correspondence: alami@gnu.ac.kr
} 
The plant also exhibits considerable antiinflammatory (Panchal et al. 2011) and antibacterial (Mottakin et al. 2004) activity.

Most of the pharmaceutical industries largely depend upon material procured from the naturally occurring stands. Because of extensive and unrestricted exploitation coupled with limited cultivation and insufficient attempts for the replenishment, the wild stock of many medicinal plants has been markedly depleted. Currently, between 4,000 and 10,000 medicinal plants are on the endangered species list and this number is expected to increase (Canter et al. 2005). W. calendulacea is also listed as an endangered species (Ahmed 1997). Thus, for sustainable utilization and to counter the over-exploitation and consequent threats to biodiversity, it should be envisioned to practice for mass multiplication and conservation of this valuable medicinal plant.

In recent years, there has been an increased interest in in vitro culture techniques, which offer a viable tool for mass multiplication and germplasm conservation of rare, endangered and threatened medicinal plants (Radmann et al. 2011; da Silva et al. 2012; Ouyang et al 2012; Silveira et al. 2013). Somatic embryogenesis has been proved to be useful and efficient method for mass clonal propagation of selected material, production of mutants and artificial seeds, genetic engineering and germplasm cryopreservation (Gonzalez-Arnao et al. 2008; Hasbullah et al. 2013). Plant regeneration (i.e. micropropagation) through somatic embryogenesis could be a reliable alternative to obtain large numbers of plants with clonal fidelity (Chen et al. 2012). Large-scale somatic embryo production in automated bioreactor can be useful for the production of medicinal raw materials for pharmacologically active components (Shin and Kim 2012). It is also useful in establishing breeding material from the wild populations and in mass-producing material for selection (Tapia et al. 2009). Besides en masse propagation, it also serves as a potential model system for studying the fundamental regulatory events of plant morphogenesis in vitro (Scheidt et al. 2011).

Genetic improvement is another approach to augment the drug-yielding capacity of the plant. Genetic manipulation of the medicinal plants facilitates engineering secondary product metabolic pathways for which efficient in vitro plant regeneration systems is essential. Very little work has been undertaken on the selection and improvement for developing suitable varieties of the medicinal plants (Rao and Arora 2004). Thus, there is an immense possibility to develop the cultivars with desired traits allowing a target cell to regenerate in vitro into a new plant. Induction of somatic embryos in $W$. calendulacea could offer a powerful tool to reach this goal. Therefore, it is important to develop a protocol for somatic embryogenesis for this species to rapidly disseminate the superior clones once they are identified and also to develop new varieties. Micropropagation of $W$. calendulacea through axillary bud proliferation has been reported (Emmanuel et al. 2000). To-date, there are no reports on plant regeneration via somatic embryogenesis of this species. The present study studied the plant regeneration through somatic embryogenesis from leaf and internode derived callus of $W$. calendulacea, together with a histological analysis of the development of the somatic embryos.

\section{MATERIALS AND METHODS}

\section{Plant material and explant source}

Primary calluses were induced from the leaf and internode explants excised from in vitro-cloned shoots. For establishing in vitro plantlets, nodal segments of field grown plant were surface sterilized with $0.1 \%(\mathrm{w} / \mathrm{v})$ mercuric chloride and cultured on MS medium (Murashige and Skoog 1962), supplemented with $0.5 \mathrm{mg} \mathrm{L}^{-1}$ BAP plus $0.1 \mathrm{mg} \mathrm{L} \mathrm{L}^{-1} \mathrm{GA}_{3}$ and incubated in a growth chamber maintained at $25^{\circ} \mathrm{C}$ under a $16 / 8 \mathrm{~h}$ (light/dark) photoperiod with a photosynthetically active radiation of $28-30 \mu \mathrm{mol} \mathrm{m} \mathrm{m}^{-2} \mathrm{~s}^{-1}$ (supplied by the cool-white fluorescent lamps, Leo Light, Korea). Similar physical environment was maintained in the following experiments. Multiple shoots were maintained by periodic subculturing for supplying the explants.

\section{Callus induction, proliferation and maintenance}

Leaf disc (3-5 $\mathrm{mm}$ of diameter) and thin internode slices $(2-3 \mathrm{~mm})$ were placed on MS semi-solid medium, supplemented with different concentrations of 2,4-D or NAA alone or NAA in combination with BAP and incubated at light condition for callus induction. Induced calluses were subcultured into fresh media at 21-28 days interval for developing embryogenic nature. Blackened and dead portion of the callus were 
discarded during every subculture. Friable, nodular calluses were assumed as potentially embryogenic (considered as effective callus) and were selected for maintenance and regeneration.

\section{Induction of somatic embryogenesis}

After 8-9 weeks of culture, the proliferated friable granular calluses were subcultured on fresh medium containing same or reduced concentrations 2,4-D for induction and maturation of somatic embryogenesis. Medium devoid of PGR $\left(\mathrm{MS}_{0}\right)$ was also tested for this purpose.

\section{Somatic embryo germination and plantlet conversion}

For embryo germination, somatic embryos were transferred to MS basal medium, supplemented with different concentrations of BAP and $\mathrm{GA}_{3}$, alone or combined. In all the cases, $3 \%(\mathrm{w} / \mathrm{v})$ sucrose (Phytotechnology laboratories, USA) was used as carbon sources. $\mathrm{pH}$ of the media were adjusted to 5.7 prior to gelling with $0.8 \%$ agar $(\mathrm{w} / \mathrm{v})$ (BHD, England) and sterilized by autoclaving at $121^{\circ} \mathrm{C}$ for $20 \min \left(1.06 \mathrm{~kg} \mathrm{~cm}^{-2}\right)$.

\section{Rooting, acclimatization and transfer to soil}

In some cases, somatic embryos showed only shoot development. These partially converted somatic embryos were transferred to MS medium containing different concentrations of NAA $(0.1$ to $2.0 \mathrm{mg} \mathrm{L}^{-1}$ ) for effective root development. Regenerated plantlets, with well-developed root, were acclimatized as described previously (Khalekuzzaman et al. 2012). The plants were washed to remove agar and then transferred to the pots containing sterile vermiculite. Each pot was enclosed in a polyethylene bag after watering and maintained in a growth chamber at $25^{\circ} \mathrm{C}$ under 16 $\mathrm{h}$ illuminations $\left(45 \mu \mathrm{mol} \mathrm{m} \mathrm{m}^{-2} \mathrm{~s}^{-1}\right)$ with fluorescent lamps. Bags were progressively opened weekly. After three weeks of acclimatization, plantlets were transferred to large pots for further growth.

\section{Histological studies}

Histological study was performed as described previously (Pal et al. 2007). Briefly, embryogenic cultures at different developmental stages were fixed in FAA solution (5\% formalin, 5\% acetic acid, 45\% alcohol) following Johansen (1940). The fixed materials were dehydrated through a grade series of ethanol and absolute ethanol with chloroform before they were embedded in paraffin blocks. The sections were prepared at $12 \mu \mathrm{m}$ thickness using a rotatory microtome (The Cambridge Rocker) and were stained with safranin-orange-G and tannic acid.

\section{Data recording and statistical analysis}

To evaluate the callus induction efficiency, percentage of cultures showing embryogenic callus induction and weight of the effective callus were calculated. Plant regeneration efficiency was assessed in terms of percentage of culture formed somatic embryos and followed by subsequent of shoot development (\%). Each treatment contained 25 replications and the whole experiment was repeated three times. Statistical analysis of the data was performed using SPSS software (version 11.5). A one-way analysis of variance (ANOVA) was used to evaluate the effect of growth regulators on the weight of internodes and leaf disc and also the formation of somatic embryos. Within the treatment groups, data were analyzed by one-way ANOVA, followed by Tukey's Honestly Significant Difference (HSD) test as post hoc comparison. Results were expressed as the mean $\pm \mathrm{SE}$ and differences in mean values were considered to be statistically significant at $\mathrm{p}<$ 0.05 .

\section{RESULTS}

\section{Callus induction}

Multiple shoots proliferated from the cultured nodal segments provided adequate explant for callus induction. Both internode and leaf disc produced callus on cut surface within one week of inoculation in all the treatments. Nevertheless, the texture, type and amount of callus varied with the type of growth regulator used. The highest frequency of friable callus induction was observed in MS medium containing $2.0 \mathrm{mg} \mathrm{L}^{-1} 2,4-\mathrm{D}$ from both the explants (Table 1). Higher concentration of 2,4-D suppressed callusing, cultures became brown and subsequently died. No callus was formed in the medium without PGR, rather the explants showed slight swelling initially and then turned into brown, leading to death in four weeks of culture. Compact and green colored calluses were induced rapidly when the explants were cultured on various concentrations of NAA alone or with BAP (75-80\%, no marked difference).

Those calluses continued to escalate their volume upon subculture but failed to develop any somatic embryos. Nevertheless, these calluses might have 
organogenic potential. By contrast, callus produced in 2,4-D containing medium was granular and blackish in color (Fig. 1A). This characteristic blackish calluses were not produced in any other treatments used and formed some embryogenic structure upon subsequent subcultures. Cultures incubated in continuous dark led to browning and death of tissue, instead of callus formation or further proliferation. Source of the explants also affected callus formation. Leaf disc were found better than internode segments for initial culture establishment.

Table 1 - Callus induction from different explants Wedelia calendulacea on MS medium supplemented with different concentrations of 2,4-D. Data were recorded after 6 weeks of culture. Callus fresh weight includes only effective callus. Values are the means \pm standard error. Different superscripts in the same column indicate significant differences within treatments (Tukey's HSD test, $\mathrm{p}<0.005$ ).

\begin{tabular}{|c|c|c|c|c|}
\hline \multirow[t]{2}{*}{$\begin{array}{l}\text { Concentration } \\
\text { of } \\
2,4-\mathrm{D}\left(\mathrm{mg} \mathrm{L}^{-1}\right)\end{array}$} & \multicolumn{2}{|c|}{$\begin{array}{l}\text { Frequency } \\
\quad(\%)\end{array}$} & \multicolumn{2}{|c|}{$\begin{array}{l}\text { Fresh wt } \\
\quad(\mathrm{mg})\end{array}$} \\
\hline & Internode & $\begin{array}{l}\text { Leaf } \\
\text { disc }\end{array}$ & Internode & Leaf disc \\
\hline 0.5 & 40 & 44 & $525.2 \pm 1.5^{\mathrm{a}}$ & $567.4 \pm 1.27^{\mathrm{a}}$ \\
\hline 1.0 & 64 & 72 & $736.6 \pm 2.2^{\mathrm{c}}$ & $875.6 \pm 1.6^{\mathrm{c}}$ \\
\hline 2.0 & 84 & 92 & $875.0 \pm 2.0^{\mathrm{e}}$ & $991.3 \pm 2.1^{\mathrm{e}}$ \\
\hline 2.5 & 72 & 84 & $822.9 \pm 1.8^{\mathrm{d}}$ & $925.6 \pm 1.6^{\mathrm{d}}$ \\
\hline 3.0 & 44 & 52 & $593.1 \pm 3.1^{\mathrm{b}}$ & $599.4 \pm 1.7^{\mathrm{b}}$ \\
\hline
\end{tabular}

\section{Induction of somatic embryogenesis}

The calluses became embryogenic after $2^{\text {nd }}$ and subsequent subcultures and began to form somatic embryo in a reduced level of 2,4-D and was most effective at $0.5 \mathrm{mg} \mathrm{L}^{-1}$. Somatic embryos were developed in up to $76 \%$ of cultures (Table 2). Calluses failed to undergo somatic embryo differentiation when 2,4-D concentration remained the same as the proliferation medium. On the other hand, in PGR-free $\left(\mathrm{MS}_{0}\right)$ medium, no further differentiation was observed and cultures gradually became necrotic. Upon transfer on the embryo formation medium, calluses became creamy in color and more granular, and turned into globular structures in the second week (Fig. 1B). A number of embryo-like cells grew into heart shaped structure in third week, which was also evidenced from the histological studies (Fig. $1 \mathrm{C}, \mathrm{D}, \mathrm{G})$. In the fourth week and onward, some heart shaped embryos differentiated into torpedo shaped (Fig. 1E) and subsequently cotyledonary stage (Fig. 1F). Histological examinations revealed the structure of somatic embryos with shoot and root pole having provascular strands (Fig. 1H, I).

Table 2 - Development of somatic embryos after subculturing the embryogenic callus of Wedelia calendulacea on different reduced concentration of 2,4D. Data were recorded after 6 weeks of culture. Values are the means \pm standard error. Different superscripts in the same column indicates significant differences within treatments (Tukey's HSD test, $\mathrm{p}<0.005$ ).

\begin{tabular}{ccc}
$\begin{array}{c}\text { Concentration of } \\
\text { 2,4-D }\left(\mathbf{m g ~ L}^{-1}\right)\end{array}$ & $\begin{array}{c}\text { Frequency of SE } \\
\text { formation }(\%)\end{array}$ & $\begin{array}{c}\text { Number of SE } \\
\text { per culture }\end{array}$ \\
\hline 0.0 & - & - \\
0.1 & 40 & $18.08 \pm 1.06^{\mathrm{a}}$ \\
0.5 & 76 & $56.04 \pm 1.46^{\mathrm{c}}$ \\
1.0 & 36 & $31.76 \pm 1.90^{\mathrm{b}}$ \\
2.0 & - & - \\
\hline
\end{tabular}

\section{Maintenance of embryogenic callus}

Callus size and fresh weight increased substantially through the subculturing in $2.0 \mathrm{mg} \mathrm{L}^{-1} 2,4-\mathrm{D}$ containing medium until sixth subculture, almost three fold effective callus was obtained within 3-4 weeks on average. After that the rate of callusing decreased to some extent. No noticeable variation was observed in the regeneration rate when callus were taken from 9 to 21 weeks old cultures (data not shown).

\section{Plantlet conversion from somatic embryos}

Somatic embryos were unable to germinate on the induction medium. Cultures having cotyledonary embryos exhibited plantlet conversion when transferred to the germination media. Combination of $\mathrm{BAP}$ with $\mathrm{GA}_{3}$ induced maximum germination rate and highest number of embryos (68\%) showing germination (shoot development) in medium containing $1.0 \mathrm{mg} \mathrm{L}^{-1} \mathrm{BAP}$ plus $0.5 \mathrm{mg}$ $\mathrm{L}^{-1} \mathrm{GA}_{3}$ (Fig. 1J) (Table 3). On the other hand, only a few number of embryos germinated successfully when $\mathrm{BA}$ or $\mathrm{GA}_{3}$ was used as the sole growth regulator. An increased $\mathrm{BAP} / \mathrm{GA}_{3}$ ratio suppressed plant development. The somatic embryos showed frequent normal germination with simultaneous shoot and root development (Fig. 1K). In some cases, only shoots were formed, and rarely, only roots developed. No secondary embryogenesis was observed. 


\section{Rooting and acclimatization}

Partially converted embryos having only shoots were transferred to rooting media containing different concentration of NAA to develop a healthy root system. Almost $100 \%$ of the shoots produced roots in the media containing $0.5 \mathrm{mg} \mathrm{L}^{-1}$ NAA. Higher concentration of NAA suppressed root formation and unexpected basal callusing. On the other hand, lower concentration of NAA delayed root formation (data not shown). Around $65 \%$ of plantlets survived after transfer to soil condition (Fig. 1L).
Table 3 - Germination of somatic embryos of Wedelia calendulacea into plantlets after culturing on MS medium fortified with BAP and $\mathrm{GA}_{3}$. Embryos were cultured for 6 weeks in the germination medium.

\begin{tabular}{ccc}
\hline $\begin{array}{c}\text { Growth Regulators } \\
\left(\mathbf{m g ~ L}^{-1}\right)\end{array}$ & $\begin{array}{c}\text { Frequency of } \\
\text { Germination (\%) }\end{array}$ \\
\hline BAP & $\mathbf{G A}_{3}$ & \\
\hline 0.5 & & 12 \\
1.0 & & 32 \\
1.5 & & 20 \\
2.0 & 1.0 & 16 \\
& 1.5 & 20 \\
& 2.0 & 12 \\
0.5 & 0.1 & 40 \\
1.0 & 0.1 & 24 \\
1.0 & 0.5 & 68 \\
2.0 & 0.5 & 48 \\
0 & 0 & - \\
\hline
\end{tabular}
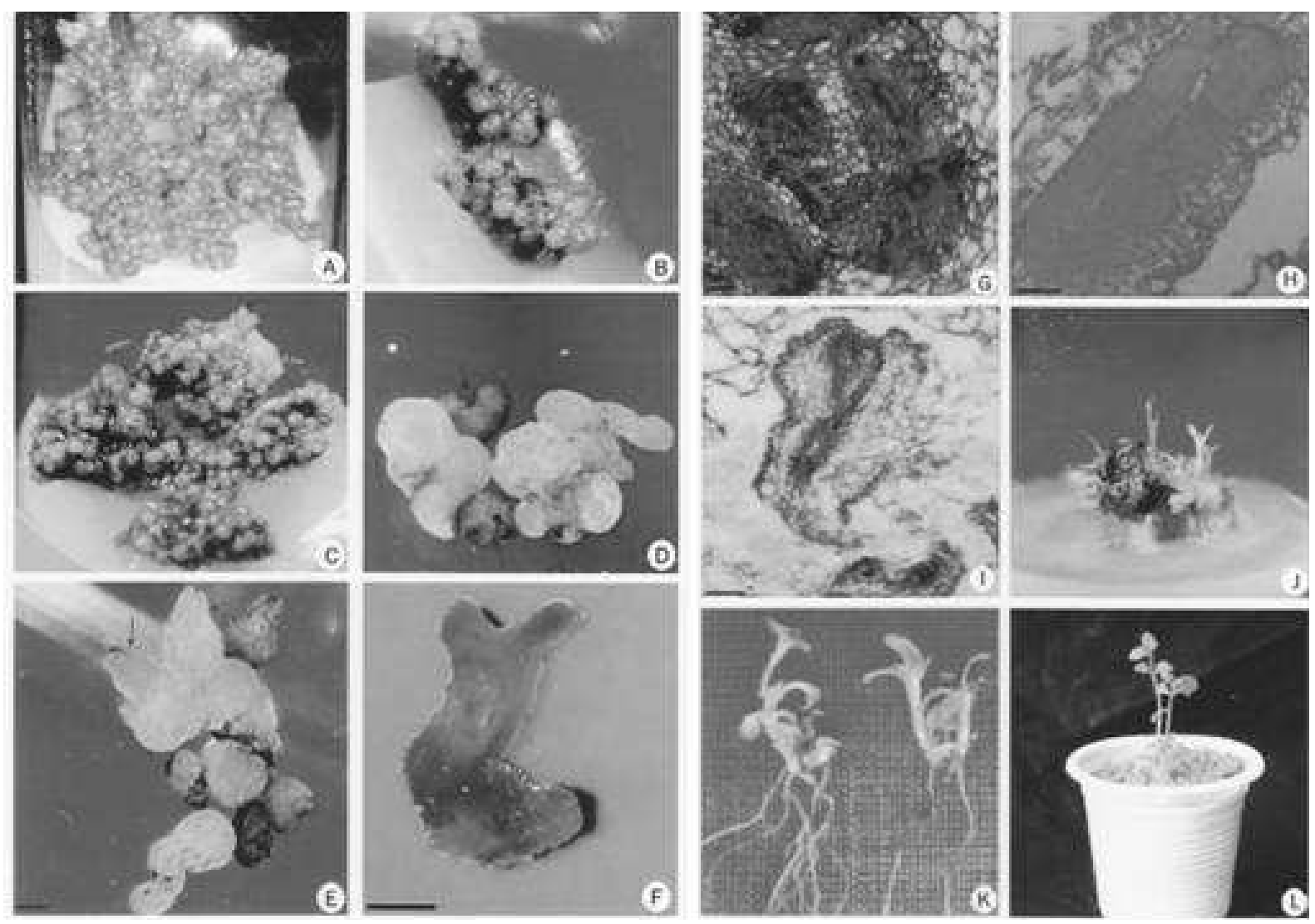

Figure 1 - Somatic embryogenesis and plant regeneration in Wedelia calendulacea. Friable embryogenic callus developed from leaf disc (A), formation of globular structure (B), development of different types of somatic embryo on embryogenic callus (C), embryo clumps showing heart-shaped and early torpedo-shaped somatic embryos (D, E), somatic embryo showing two cotyledons and a root pole $(\mathrm{F})$. Histological section showing heart shaped $(\mathrm{G})$, torpedo shaped $(\mathrm{H})$ and cotyledonary somatic embryo (I). Plant regeneration from somatic embryo clumps $(\mathrm{J})$, plantlet with root $(\mathrm{K})$, acclimatized plantlet in soil (L). Bars: E, F 1mm; G, H, I 0.5mm. 


\section{DISCUSSION}

Somatic embryogenesis is a multi-step regeneration process starting with formation of proembryogenic masses, followed by somatic embryo formation, maturation, desiccation and plant regeneration (von Arnold et al. 2002). These steps are characterized by a complete reorganization of the cellular state, including physiology, metabolism and gene expression and begin a new life cycle. Somatic embryogenesis of $W$. calendulacea appears to involve phases of cell division, callus initiation, formation of early-stage embryos, maturation of embryos and conversion into plantlets.

Auxin, particularly 2,4-D was believed to be the most trustworthy growth regulator for the induction of somatic embryogenesis. Embryogenic callus induction using 2,4-D has been reported in a number of medicinal plants (Kim et al. 2011). Callus or a cell suspension growing in a medium supplemented with a moderate dose of 2,4-D to a reduced amount of the auxin, was adopted as the standard protocol in inducing somatic embryogenesis in many species, including a number of medicinal plants (Thorpe and Stasolla 2001, Raghavan 2004, Quiroz-Figueroa et al. 2006). Acquisition of embryogenic competence largely depends on dedifferentiation when the existing developmental information must be stopped or altered in order to make the cells responsive for new signals. It is generally accepted that the reactivation of cell division in somatic cells is required for dedifferentiation and the establishment of embryogenic competence. In the present study, concentration of 2,4-D for somatic embryo development showed a pivotal role during subculture. Unorganized calluses did not undergo differentiation until it reduced to an optimum level. Failure to develop the somatic embryo in PGR-free medium indicates the essentiality of a low concentration of 2,4-D for switching to the somatic to embryogenic pathway, which justifies earlier findings. Removal of auxin from the culture medium could inactivate several genes or synthesize new gene-products necessary for the successful completion of embryo development (Zimmerman 1993). In contrast, the continuous presence of 2,4-D has been shown to block embryo differentiation as observed in Catharanthus roseus (Junaid et al. 2006). Most of the transformation procedures rely on retaining long-term morphogenic potential after repeated subculture, and this is critical for successful transformation. Wedelia calendulacea callus retained high regeneration competence for a long period of time without substantial alteration in regeneration frequency. This aspect of $W$. calendulacea callus culture could be useful for the utilization of transformation in this valuable plant. Nevertheless, further study should be conducted to explore for possible genetic alterations. Although the callus maintains its regeneration capacity for a longer period, prolonged subculturing may lead to accumulation of mutations, especially in higher concentrations of 2, 4-D (Pal et al. 2007). Adverse effect of prolonged in vitro culture is reported by many workers (Jureti and Jelaska 1991, Choi et al. 2001). On the other hand, somaclonal variation can arise, which is a useful source of new variation for genetic breeding (Carvalho et al. 2013).

Germination of somatic embryos and its conversion into plantlets are crucial steps for the successful plant regeneration. Exogenous plant growth regulator has an important function in this morphogenic event. In the present study, among different treatments, BAP in combination with $\mathrm{GA}_{3}$ gave efficient embryo germination, while fewer plantlets developed when used solely. Positive effect of BAP and kinetin has been reported in organogenic mode of shoot formation and elongation in this species (Emmanuel et al. 2000). Synergistic effect of cytokinin and gibberellin in promoting the conversion of embryos to plantlets has also been reported in a number of species (Zlenko et al. 2002, Martin 2004, Paramageetham et al. 2004, CangahualaInocente et al. 2007, Junaid et al. 2007). GA 3 also have been used in the elongation of regenerated shoots (Lakshmi et al 2013). The effectiveness of $\mathrm{GA}_{3}$ could be due to gene activation or synthesis of new gene-products for the completion of embryo development. In some cases, failure of producing effective roots might be associated with meristem malfunction or asynchronous growth and requires an additional rooting step to recover complete plantlet as reported in some other species (Martin 2004, Karami et al. 2006, Pacheco et al. 2007). Optimized rooting using NAA is a very common in plant tissue culture. In the present study, light was found essential for the entire morphogenic pathway. Positive effect of light is for somatic embryogenesis has been demonstrated earlier also (Manrique and Roca 1987). 


\section{CONCLUSION}

Wedelia calendulacea is an endangered medicinal plant that received little attention from plant biotechnologist. For the first time, a plant regeneration protocol was developed in this study via somatic embryogenesis from leaf and internode derived callus for this species. This protocol could facilitate rapid propagation and conservation of this endangered species. It also opens an opportunity to improve the plant through transgenic approach. Moreover, secondary metabolite production could be possible for pharmacologically active compounds.

\section{ACKNOWLEDGEMENTS}

This work was supported by the Ministry of Science Information \& Communication Technology, Government of the People's Republic of Bangladesh (grant to SA Sharmin). SA Sharmin was also a recipient of the Prime Minster Fellowship, GoB.

\section{REFERENCES}

Ahmed N. Wild flowers of Bangladesh. The University press Limited, Dhaka, Bangladesh. 1997.

Annie S, Prabhu RG, Malini S. Activity of Wedelia calendulacea Less. in post-menopausal osteoporosis. Phytomedicine. 2006; 13:43-8.

Cangahuala-Inocente GC, Vesco LLD, Steinmacher D, Torres AC, Guerra MP. Improvements in somatic embryogenesis protocol in Feijoa (Acca sellowiana (Berg) Burret): Induction, conversion and synthetic seeds. Sci Hortic. 2007; 111: 228-234.

Canter PH, Thomas H, Ernst E. Bringing medicinal plants into cultivation: opportunities and challenges for biotechnology. Trends Biotechnol. 2005; 23: 180185.

Carvalho DC, Silva ALL, Schuck MR, Purcino M, Tanno GN, Biasi LA. Fox grape cv. Bordô (Vitis labrusca L.) and grapevine cv. Chardonnay (Vitis vinifera L.) cultivated in vitro under different carbohydrates, amino acids and 6-Benzylaminopurine levels. Braz Arch Biol Technol. 2013; 56(2): 191-201.

Chen K, Wu HJ, Chen JF, Cheng XF, Jing X, Wang $\mathrm{XY}$. Somatic embryogenesis and mass spectrometric identification of proteins related to somatic embryogenesis in Eruca sativa. Plant Biotechnol Rep. 2012; 6: 113-122.
Choi H, Lemaux PG, Cho M. Selection and osmotic treatment exacerbate cytological aberrations in transformed barley (Hordeum vulgare L.). J Plant Physiol. 2001; 158: 935-943.

da Silva ALL, Costa JL, Alcantara GB, Carvalho DC, Schuck MR, Biasi LA et al. Micropropagation of Nidularium innocentii Lem. and Nidularium procerum Lindm. (Bromeliaceae). Pak J Bot. 2012; 44(3): 1095-1101.

Emmanuel $\mathrm{S}$, Amalraj $\mathrm{T}$, Ignacimuthu $\mathrm{S}$. Hepatoprotective effect of coumestans isolated from the leaves of Wedelia calendulacea Less. in paracetamol induced liver damage. Indian J Exp Biol. 2001; 39: 1305-7.

Emmanuel S, Ignacimuthu S, Kathiravan K. Micropropagation of Wedelia calendulacea Less. A Medicinal Plant. Phytomorphology. 2000; 50: 195200.

Gonzalez-Arnao MT, Panta A, Roca WM, Escobar RH, Engelmann F. Development and large scale application of cryopreservation techniques for shoot and somatic embryo cultures of tropical crops. Plant Cell Tiss Organ Cult. 2008; 92:1-13.

Hasbullah NA,Taha RM, Saleh A, Mohamed N. Physiological responses of callus from Gerbera jamesonii Bolus ex. Hook f. to gamma irradiation. Braz Arch Biol Technol. 2013; 55: 411-416.

Johansen DA. Plant Micro Techique. New York: McGraw-Hill. 1940.

Junaid A, Mujib A, Bhat MA, Sharma MP, Šamaj J. Somatic embryogenesis and plant regeneration in Catharanthus roseus. Biol Plant. 2007; 51: 641-646.

Junaid A, Mujib A, Bhat MA, Sharma MP. Somatic embryo proliferation, maturation and germination in Catharanthus roseus. Plant Cell Tiss Organ Cult. 2006; 84: 325-332.

Jureti B, Jelaska S. Plant development in long-term embryogenic callus lines of Cucurbita pepo. Plant Cell Rep. 1991; 9: 623-626.

Karami O, Deljou A, Esna-Ashari M, Ostad-Ahmadi P. Effect of sucrose concentrations on somatic embryogenesis in carnation (Dianthus caryophyllus L.). Sci Hortic. 2006; 110: 340-344.

Khalekuzzaman M, Khatun MM, Rashid MH, Sheikh MMI, Sharmin SA, Alam I. Micropropagation of an elite F1 watermelon (Citrullus lanatus) hybrid from the shoot tip of field grown plants. Braz Arch Biol Technol. 2012; 55: 335-34.

Kim JA, Kim YS, Choi YE. Triterpenoid production and phenotypic changes in hairy roots of Codonopsis lanceolata and the plants regenerated from them. Plant Biotechnol Rep. 2011; 5:255-263. 
Lakshmi SR, Benjamin JHF, Kumar TS, Murthy GVS, Rao MV. Organogenesis from in vitro-derived leaf and internode explants of Hoya wightii ssp. palniensis - a vulnerable species of Western Ghats. Braz Arch Biol Technol. 2013; 56: 421-430.

Manrique SL, Roca W. Effect of photoperiod and culture medium in somatic embryogenesis and the histological analysis of the process in cassava. Manihot esculenta. Crantz Acta Agro. 1987; 37: 7-18.

Martin KP. Efficacy of different growth regulators at different stages of somatic embryogenesis Eryngium foetidum L.-A rare medicinal plant. In vitro Cell Dev Biol Plant. 2004; 40: 459-463.

Mottakin AKM, Chowdhury R, Haider MS, Rahman KM, Hasan CM, Rashid MA. Cytotoxicity and antibacterial activity of extractives from Wedelia calendulacea. Fitoterapia. 2004; 75: 355-359.

Murashige T, Skoog F. A revised medium for rapid growth and bioassay with tobacco tissue culture. Plant Physiol. 1962; 15: 473-497.

Ouyang L, Huang Z, Zhao L, Sha Y, Zeng F, Lu X. Efficient regeneration of Eucalyptus urophylla $\times$ Eucalyptus grandis from stem segment. Braz Arch Biol Technol. 2012; 55: 329-334.

Pacheco G, Gagliardi RF, Carneiro LA, Callado CH, Valls JFM, Mansur E. The role of BAP in somatic embryogenesis induction from seed explants of Arachis species from sections erectoides and procumbentes. Plant Cell Tiss Organ Cult. 2007; 88:121-126.

Pal SP, Alam I, Anisuzzaman M, Sarker KK, Sharmin SA, Alam MF. Indirect Organogenesis in summer squash (Cucurbita pepo L.). Turk J Agric For. 2007; 31: 63-70.

Panchal A H. Patel Rakesh K, Pundarikakshudu K, Bhandari A. Evaluation of anti-inflammatory activities of extract of leaves of Eclipta alba and Wedelia calendulacea. IJPS. 2011; 3: 1846-1852.

Paramageetham Ch, Babu GP, Rao JVS. Somatic embryogenesis in Centella asiatica L. an important medicinal and neutraceutical plant of India. Plant Cell Tissue Organ Cult. 2004; 79: 19-24.

Quiroz-Figueroa FR, Rojas-Herrera R, Galaz-Avalos RM, Loyola-Vargas VM. Embryo production through somatic embryogenesis can be used to study cell differentiation in plants. Plant Cell Tiss Organ Cult. 2006; 86:285-301.

Radmann, Elizete B. In vitro multiplication of 'Flordaguard' rootstock: cytokinin source and concentration effects, explants orientation and period of permanence in the culture medium. Braz arch biol Technol. 2011; 54:25-34.
Raghavan V. Role of 2, 4-dichlorophenoxyacetic acid (2,4-D) in somatic embryogenesis on cultured zygotic embryos of Arabidopsis: cell expansion, cell cycling, and morphogenesis during continuous exposure of embryos to 2,4-D. Am J Bot. 2004; 91: 1743-1756.

Rao VR, Arora RK. Rationale for conservation of medicinal plants. In: Batugal, Pons A, Kanniah J, Young LS, Oliver JT (eds) Medicinal plants research in Asia, Volume 1: The framework and project workplans. International Plant Genetic Resources Institute- Regional Office for Asia, the Pacific and Oceania (IPGRI-APO), Serdang, Selangor DE, Malaysia. 2004.

Scheidt GN, da Silva ALL, Oliveira Y, Costa JL, Biasi LA, Soccol CR. In vitro growth of Melaleuca alternifolia Cheel in bioreactor of immersion by bubbles. Pak J Bot. 2011; 43(6): 2937-2939.

Shin H, Kim YW. Somatic embryogenesis of Pinus rigida $\times P$. taeda and the relationship between the initiation of embryogenic tissue and zygotic embryo development. Plant Biotechnol Rep. 2012; 6:175-181.

Silveira DG, Lino LSM, Souza ADS, Souza FVD. Somatic embryogenesis of Neoglaziovia variegata (Arruda) Mez, an important source of fiber from native Brazilian bromeliads. Braz Arch Biol Technol. 2013; 56: 547-555.

Tapia E, Sequeida Á, Castro Á, Montes C, Zamora P, López $\mathrm{R}$, et al. Development of grapevine somatic embryogenesis using an air-lift bioreactor as an efficient tool in the generation of transgenic plants. $J$ Biotechnol. 2009; 139: 95-101.

Thorpe TA, Stasolla C. Somatic embryogenesis. In: Bhojwani SS, Soh WY (eds) Current trends in the embryology of angiosperms. Kluwer Academic Publishers, Dordrecht: Netherlands. 2001; 279-336.

Varsha K, Nema AK, Agarwal A. Hepatoprotective prospective of herbal drugs and their vesicular carriers-A review. IJPBR. 2011; 2: 360-374.

von Arnold S, Sabala I, Bozhkov P, Dyachok J, Filonova L. Developmental pathways of somatic embryogenesis. Plant Cell Tissue Organ Cult. 2002; 69: 233-249.

Zimmerman JL. Somatic embryogenesis- A model for early development in higher plants. Plant Cell. 1993; 5: 1411-1423.

Zlenko VA, Kotikov IV, Troshin LP. Efficient $\mathrm{GA}_{3}$ assisted plant regeneration from cell suspensions of three grape genotypes via somatic embryogenesis. Plant Cell Tissue Organ Cult. 2002; 70: 295-299.

Received: March 13, 2013; Accepted: January 13, 2014. 